\title{
THE STUDY ON DEVELOPMENT OF LIGHT-WEIGHT FOAMED MORTAR FOR TUNNEL BACKFILL
}

\author{
Sang-Joon Ma \\ Geotechnical Infrastructure Research Department, Korea Institute of Construction Technology, 1190, \\ Simindae-Ro, Ilsanseo-Gu, Goyang-Si, 411-712, Republic of Korea \\ sjma@kict.re.kr \\ Eun-Gu Kang \\ Geotechnical Infrastructure Research Department, Korea Institute of Construction Technology \\ egkang@kict.re.kr \\ Dong-Min Kim \\ Geotechnical Infrastructure Research Department, Korea Institute of Construction Technology \\ dmkim@kict.re.kr
}

\begin{abstract}
This study was intended to develop the Light-Weight Foamed Mortar which is used for NATM Composite lining backfill. In the wake of the study, the mixing method which satisfies the requirements for compressive strength, permeability coefficient, fluidity, specific gravity and settlement was developed and moreover field applicability was verified through the model test. Thus the mixing of Light-Weight Foamed Mortar developed in this study is expected to be applicable to NATM Composite lining, thereby making commitment to improving the stability and drainage performance of lining.
\end{abstract}

Keywords: Light-Weight Foamed Mortar; NATM Composite Lining Method; Tunnel Backfill.

\section{Introduction}

When the cavity exists between the lining and the ground, the load tends to concentrate on specific part which causes the lining structure to be significantly deformed. In case of existing cast-in-place concrete lining for NATM tunnel, cavity behind the lining was often occurred which was attributed to insufficient filling or difficulty in quality control, and such problem sometimes leads to critical impact on tunnel stability ${ }^{1}$.

Existing nonwoven fabric drainage tends to be deteriorated over the time because of clogging problem and in such a case, residual water pressure threatens the stability and thus the measure to deal with such a challenge is more than important ${ }^{2}$.

This study thus was intended to develop the Light-Weight Foamed Mortar with excellent fluidity and compactibility as tunnel backfill material. The Light-Weight Foamed Mortar has higher compactibility compared to existing concrete grouting material as well as is able to minimize the possibility of cavity and effectively distribute the relaxed ground 
load to PC panel lining ${ }^{3}$. Moreover as it's porous, it functions to drain the groundwater, instead of existing nonwoven fabric, when the cavity behind the lining is filled with this mortar. And as it has larger conveyance section than existing nonwoven drainage, it's able to deal with the drainage problem caused by clogging 4 .

This study thus was intended to develop the Light-Weight Foamed Mortar which is able to convey the relaxed ground load to PC panel lining with excellent compactibility and permeability and the applicability was also evaluated.

\section{Development of Light-Weight Foamed Mortar for filling the cavity behind the panel}

\subsection{Test summary}

This study was aimed at developing the optimal Light-Weight Foamed Mortar which will have the compressive strength more than $3 \mathrm{MPa}$ with the fluidity of $180 \mathrm{~mm}$ or greater and the unit volume weight of $6.0 \sim 7.0 \mathrm{kN} / \mathrm{m}^{3}$ for the purpose of using as backfill material for the cavity behind the lining.

Mixing of Light-Weight Foamed Mortar used for the test was designed considering the compressive strength which is outlined in Table 1. Cement used was type 1 portland cement and silica sand \#4 and \#5 were added to the fine aggregate to maintain the accuracy of the test. Cement and fine aggregate contents was determined within $10 \sim 15 \%$ of cement and the cement-blast furnace slag ratio was 7 to 3 . Foaming agent was $2 \%$ of diluted volume with the $\mathrm{W} / \mathrm{C}$ ratio of $60 \sim 65 \%$. The mixing which was close the most to the target value of compressive strength and permeability coefficient of Light-Weight Foamed Mortar for using as backfill material for the cavity behind PC panel was selected and the optimal mixing ratio was finally determined after evaluating the unit quantity, foaming agent and fine aggregate.

Table 1. Test mixing ratio for Light-Weight Foamed Mortar

\begin{tabular}{|c|c|c|c|c|c|c|c|}
\hline \multicolumn{2}{|c|}{ Classification } & \multicolumn{2}{|c|}{ Mix. A $(\mathrm{W} / \mathrm{C}=60 \%)$} & \multicolumn{2}{|c|}{ Mix. $\mathrm{B}(\mathrm{W} / \mathrm{C}=65 \%)$} & \multicolumn{2}{|c|}{ Mix. $C(\mathrm{~W} / \mathrm{C}=60 \%)$} \\
\hline \multirow{2}{*}{\multicolumn{2}{|c|}{ Strength(MPa) }} & \multicolumn{2}{|c|}{$1.0 \sim 2.0$} & \multicolumn{2}{|c|}{$2.5 \sim 3.5$} & \multicolumn{2}{|c|}{$4.5 \sim 5.5$} \\
\hline & & Weight(kg) & Volume(1) & Weight(kg) & Volume(1) & Weight(kg) & Volume(1) \\
\hline \multirow{2}{*}{ Slurry } & Cement & 450 & 150 & 600 & 190.4 & 730 & 243.3 \\
\hline & Water & 270 & 270 & 390 & 390 & 438 & 450 \\
\hline \multicolumn{2}{|c|}{ Subtotal } & 720 & 420 & 990 & 580.4 & 1168 & 693.3 \\
\hline \multirow{2}{*}{ Foaming } & Agent & 0.7 & 0.6 & 0.52 & 0.42 & 0.4 & 0.3 \\
\hline & Water & 33.3 & 33.3 & 25.46 & 25.46 & 20.3 & 20.3 \\
\hline \multicolumn{2}{|c|}{ Subtotal } & 34.0 & 680.0 & 25.98 & 519.6 & 20.7 & 406.7 \\
\hline \multicolumn{2}{|c|}{ Total } & 754 & 1100 & 1016 & 1100 & 1189 & 1100 \\
\hline
\end{tabular}

Using a pre-foaming type, diluted water and foaming agent was mixed at 50 to 1 before compressing at $5 \mathrm{~kg} / \mathrm{cm}^{2}(490 \mathrm{kPa})$ A 60 -liter mechanical mixer was used for mixing and to minimize the antifoaming, vibrating compaction only was carried out. 
Light-Weight Foamed Mortar was cured in accordance with KS F 2459. The specimen for measuring apparent specific gravity was cured for 48 hours at room temperature and then was put into the water curing process in water tank at $21 \pm 3{ }^{\circ} \mathrm{C}$ for 28 days. The specimen to be used for compressive strength test was put into saturated moisture or the sealed plastic bag which was twice larger than the specimen and had been kept floating on the water at $20^{\circ} \mathrm{C}$ to meet the requirement of curing at $21 \pm 3{ }^{\circ} \mathrm{C}$.

\subsection{Test result}

\subsubsection{Compressive strength}

Fig. 1 below indicates the result of compressive strength test of Light-Weight Foamed Mortar which was carried out in accordance with KS F 2459. 3-day, 7-day and 28-day compressive strength was compared. When it comes to mix A, 28-day compressive strength failed to reach the target 3.0MPa and in case of mix $\mathrm{B}, 28$-day compressive strength reached $3.8 \mathrm{MPa}$ while mix $\mathrm{C}$ obtained 6.2MPa. Comparing amount of Cement between mix $\mathrm{A}$ and $\mathrm{B}$, increase in strength of mix $\mathrm{C}$ appeared to be significant, which appeared to be attributable to reduced total voids resulting from relatively smaller foaming agent due to increased water when increasing Cement.

\subsubsection{Coefficient of permeability}

The Light-Weight Foamed Mortar to be developed is for filling the cavity behind the tunnel and shall serve the medium which will distribute the stress caused by ground relaxation and underground inflow to the lining as well as have drainage function. Hence, light weigh foamed mortar for NATM Composite lining shall have the permeability coefficient of $10^{-2} \sim 10^{-3} \mathrm{~cm} / \mathrm{sec}$ or greater and the permeability capacity of Light-Weight Foamed Mortar was evaluated in accordance with KS F 2322 test.

The test result is outlined in Fig. 2. Mix A indicated the permeability coefficient of 2.7 5.2 $\times 10^{-2} \mathrm{~cm} / \mathrm{sec}$ and mix $\mathrm{B}$ and $\mathrm{C}$ also showed the value similar with or exceeding the target, demonstrating all three mix types will have sufficient permeability function when applied as tunnel lining backfill material

\subsubsection{Flow test}

Application of Light-Weight Foamed Mortar for tunnel backfill is carried out in a way of installing grouting plant outside the tunnel and the mortar flows into the site through the hose because of limited site space as well as for efficient application. Thus, to ensure the cavity will be fully filled without leaving any void, liquidity serves the critical role. The flow test to evaluate the fluidity of Light-Weight Foamed Mortar was conducted in accordance with KS F 4039. Flow value of $180 \mathrm{~mm}$ which was set as the reference value in this study is able to pump the material for $500 \mathrm{~m}$ without segregation. The flow test result is summarized in Fig. 3. According to the test result, mix A and B indicated $236 \mathrm{~mm}$ and $196 \mathrm{~mm}$, respectively which were considered to be acceptable fluidity, while mix $\mathrm{C}$ indicating $164 \mathrm{~mm}$ would possibly cause the problem in filling process. 


\subsubsection{Apparent specific gravity}

It's desirable for Light-Weight Foamed Mortar to have lower specific gravity because it would impose the load on lining during ground relaxation. Thus in this study, apparent specific gravity test according to KS F 2458 was carried out. 0.6 0.7 of apparent specific gravity was set as the target value. As a result of the test, mix A indicated 0.548 and mix $\mathrm{B}$ indicated 0.686 . both of which satisfied the requirement but mix $\mathrm{C}$ indicating 0.961 was inappropriate for use as backfill material. Fig. 4 illustrated the apparent specific gravity test result.

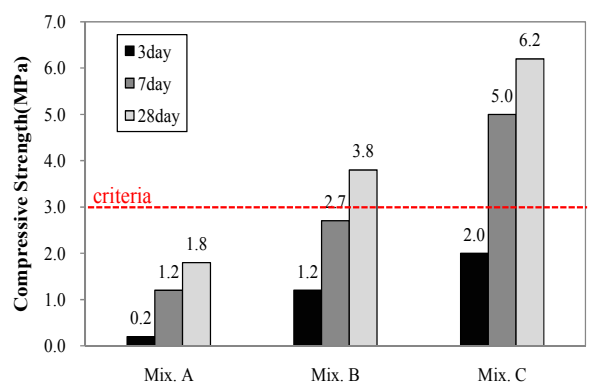

Fig. 1. Result of compressive strength test

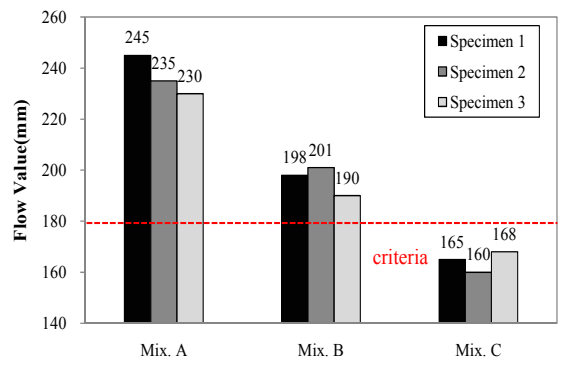

Fig. 3. Results of flow test

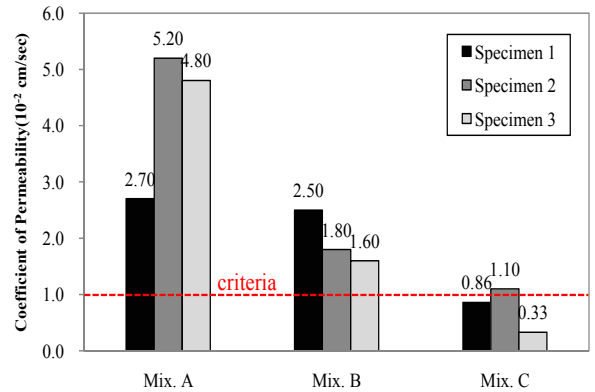

Fig. 2. Result of permeability test

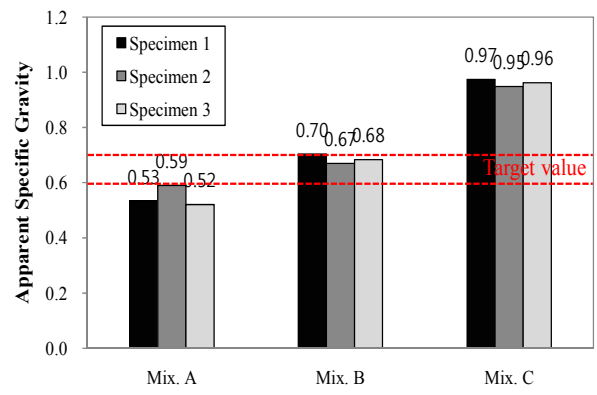

Fig. 4. Result of apparent specific gravity

\subsubsection{Settlement}

Excessive water or foam in mixing or unstable air void causes the settlement which will result in error in thickness of foam concrete and the close pore tends to turn to open pore when excessive settlement occurs, which causes the critical impact on quality of light weight foam mortar. Thus in this study, settlement occurred during curing process was measured in accordance with KS F 4039.

Table 2 shows the settlement test result. When it comes to 3 mixing adopted in this study, apparent specific gravity was 0.5 or more which corresponds to 0.6 by $\mathrm{KS}$ requirement and thus the settlement shall be less than $6 \mathrm{~mm}$. Then in case of mix A, it's $6.3 \mathrm{~mm}$ and mix B indicated $4.2 \mathrm{~mm}$ and $\mathrm{C}$ indicated $3.0 \mathrm{~mm}$. Viewing this, mix A would possibly cause somewhat excessive settlement which may have impact on quality, while 
mix B and C were acceptable and would not cause any discontinuity by settlement or construction joint. Table 2 shows the settlement test result of lightweight foamed mortar.

Table 2. Settlement test result of Light-Weight Foamed Mortar

\begin{tabular}{|c|c|c|c|c|c|c|}
\hline \multirow{2}{*}{ Designation } & \multicolumn{3}{|c|}{ Specimen No. } & \multirow{2}{*}{ Mean } & \multirow{2}{*}{ Criteria } & \multirow{2}{*}{ Evaluation } \\
\hline & 1 & 2 & 3 & & & \\
\hline Mix. A & 6.5 & 6.0 & 6.5 & 6.3 & \multirow{3}{*}{$\leq 6.0$} & Inappropriate \\
\hline Mix. B & 4.0 & 4.5 & 4.0 & 4.2 & & Appropriate \\
\hline Mix. C & 2.5 & 3.5 & 3.0 & 3.0 & & Appropriate \\
\hline
\end{tabular}

In case of mix $B$, it satisfied all requirements including compressive strength, permeability coefficient, flow value, apparent specific gravity and settlement, demonstrating its excellent applicability as tunnel backfill material.

\section{Evaluation of field applicability of Light-Weight Foamed Mortar}

\subsection{Test summary}

A model filling test of mix B developed for field applicability test was carried out. A model test device was designed and the internal face was fabricated with PC panel to simulate the site condition. The injection opening was simulated on side wall and arch which is used at the site, and the gap between PC panel and shotcrete surface was designed as $150 \mathrm{~mm}$. Lining panel had $2,710 \mathrm{~mm}$ diameter, 1,530 in height and $165 \mathrm{~mm}$ in thickness. The front and rear side of lining was fabricated with transparent acrylic window to monitor the filling process and the bottom was sealed with watertight material and the joint with lining was treated with silicon so as to prevent mortar or groundwtaer from leaking during filling process. In addition, 9 groundwater input holes were provided to evaluate the drainage capacity. Fig. 5 shows the mortar filling and Fig. 6 shows the view of test equipment.

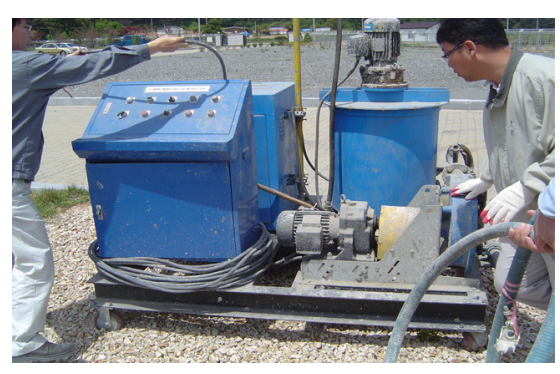

Fig. 5. Mortar filling

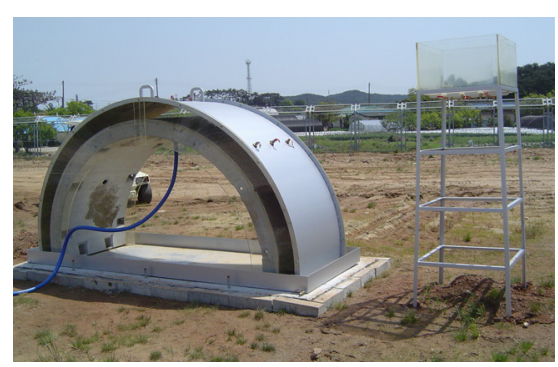

Fig. 6. Filling test equipment set

\subsection{Test result}

In the wake of model filling test of Light-Weight Foamed Mortar with injection pressure of $300 \mathrm{kPa}$ and the distance of $50 \mathrm{~m}$, no mechanical trouble with the pump, clogging or 
material segregation was occurred thanks to sufficient fluidity of the mortar. And no void behind the PC panel lining was found. As a result of drainage test, no problem was found, irrespective of the head, proving the acceptable applicability to replace the woven fabric.

\section{Conclusion}

The conclusion in the wake of carrying out the study aimed at developing the LightWeight Foamed Mortar for NATM Composite lining tunnel is highlighted as follows.

(1) As a result of developing the Light-Weight Foamed Mortar as filling material for NATM Composite lining tunnel, Mix B satisfied the requirements of compressive strength, permeability coefficient, flow value, apparent specific gravity and settlement, demonstrating the excellent performance as tunnel backfill material.

(2) As a result of model filling test to identify the field applicability of Mix. B, no mechanical trouble with the pump, clogging or material segregation was occurred without void during filling process thanks to sufficient fluidity of the mortar.

(3) The groundwater flowed into the test device was acceptably drained, irrespective of the head, demonstrating acceptable drainage performance of the mortar.

\section{Acknowledgment}

This study was carried out by assistance as part of 2009 energy technology development project by the Korea Institute of Energy Technology Evaluation and Planning(KETEP) for which I thank you so much.

\section{References}

1. S.J. Ma, H.S. Choi, D.M. Kim, H.S. Lee, K.D. Kim, An Evaluation of the mechanical Property for the Backfilling Material of the NATM Composite Lining Tunnel using the Lightweight Foamed Mortar, in Proceedings of the Korea Concrete Institute, Vol. 20, No. 1 (2008), pp. 717-720.

2. J.P. Giroud, Designing with Geotextiles, Materiaux et. Constructions, Vol. 14, No. 82 (1981), pp. 257-272.

3. S.J. Ma, H.S. Choi, D.M. Kim, P.S. Jang, An Material Experimental Study for the Development of High-Performance PC Panel, in Proceeding of KGS Fall Conference (Seoul, 2006), p. 774.

4. KICT, Development of the New NATM Composite Lining Method, KICT (2008), pp. 366-379. 